JIM 05482

\title{
An improved method for immobilizing IgG antibodies on protein A-agarose *
}

\author{
Thomas H. Sisson and C. William Castor \\ Department of Internal Medicine, Rackham Arthritis Research Unit and Rheumatology Division, \\ The University of Michigan Medical School, Ann Arbor, MI, U.S.A.
}

(Received 18 September 1989, revised received 24 October 1989, accepted 30 October 1989)

This report describes a modification of a procedure developed by others for crosslinking IgG to protein A which itself is covalently linked to a gel support. Earlier immunoaffinity columns were described as having large antigen-binding capacities and stability under a variety of elution conditions. The present data show that columns constructed with earlier techniques were only partially stable to $\mathrm{pH} 3.0$ buffers, and, as a result, bound less than $20 \%$ of the antigen predicted by theory. Modifying parameters of the dimethylpimelimidate crosslinking method led to immunoaffinity columns which did not leak immunoglobulin under low $\mathrm{pH}$ elution buffer conditions. The new immunoaffinity absorbants, because of the increased strength of the couple between the antibody and protein A, were capable of binding antigen at over $80 \%$ of their theoretical capacity.

Key words: IgG; Protein A

\section{Introduction}

The development of techniques for the production of antibody coupled immunoaffinity columns has made purification of rare proteins both simpler and more rapid. Conventional methods for immobilizing immunoglobulin via cyanogen bromide yield very stable column matrices (Axen et al., 1967). The random orientation of the coupled antibody, however, may obstruct the variable 'antigen binding' regions of the molecule, prevent-

Correspondence to: C. William Castor, University of Michigan Medical Center, Room 4570 Kresge I, Box 0531, Ann Arbor, MI 48109-0531, U.S.A.

* This work was supported by USPHS Grant AR 10728 and the Michigan Chapter, Arthritis Foundation.

Abbreviations: CTAP-III, Connective tissue activating peptide III; RID, radial immunodiffusion. ing columns generated by this approach from binding their theoretical capacity for antigen. The unpredictability of the interaction between cyanogen bromide and different types of $\mathrm{IgG}$ also hampers attempts to generate reliable antibodylinked columns.

To improve the antigen binding capacity of IgG crosslinked to column matrices, Gerston and Marchalonis (1978) linked antibody to protein A-Sepharose. Protein A binds the Fc portion of the IgG molecule, leaving the antigen specific sites free. This procedure circumvented the problem of random antibody-matrix coupling inherent in the cyanogen bromide technique. Also, the complementary interaction between protein $\mathrm{A}$ and the constant $\mathrm{Fc}$ region of the IgG molecule allowed predictable immunoglobulin immobilization, avoiding the other major drawback of the conventional procedure. Schneider et al. (1982) modified Gersten and Marchalonis's approach by gener- 
ating affinity crosslinked matrices which exhibited several desirable qualities. First, the immunoaffinity columns were stable to alkaline elution conditions and boiling in SDS. Data on acidic elution conditions, however, were not available. In addition to stability, these immunoaffinity columns had larger antigen binding capacities.

In our hands, Schneider's methodology resulted in immunoaffinity columns which were only partly stable under $\mathrm{pH}=3.0$ buffer conditions. In this study, we examined several modifications of the procedure defined by Schneider's laboratory in an effort to improve the stability of the crosslink between the protein A-gel matrix and the IgG without interfering with the optimal conformations of the immunoglobulin. We describe a method that allows the preparation of immunoaffinity columns that are both stable to acidic elution conditions, $\mathrm{pH} 3.0$, and capable of binding $50-100 \%$ of their theoretical antigen capacities.

\section{Materials and methods}

\section{Antibody generation and purification}

Antibodies to purified connective tissue activating peptide III, (CTAP-III) (Castor et al., 1983, 1989) and human albumin (Sigma Chemical Co., St. Louis, MO) were raised in New Zealand white rabbits as described previously (Castor and Cabral, 1988). These antibodies were subsequently isolated from rabbit serum using antigen coupled affinity columns that were constructed (Castor and Cabral, 1988) by immobilizing purified CTAP-III and human albumin to activated $\mathrm{CH}$ Sepharose 4B (Pharmacia Fine Chemicals, Piscataway, NJ).

\section{Generation of antibody coupled columns}

(A) Columns generated by cyanogen bromide crosslinking. Antibody was covalently crosslinked to CNBr-activated Sepharose 4B (Pharmacia) using a ligand to dry gel ratio of $25 \mathrm{mg} / \mathrm{g}$ gel. Initially the gel was swollen in ice cold $1 \mathrm{mM}$ $\mathrm{HCl}$ for $15 \mathrm{~min}$. The gel was then transferred to a sintered glass filter, washed with $200 \mathrm{ml}$ of ice cold $1 \mathrm{mM} \mathrm{HCl}$, and again swollen in $0.1 \mathrm{M}$ bicarbonate buffer containing $0.5 \mathrm{M} \mathrm{NaCl}$ (coupling buffer), $\mathrm{pH}$ 8.2. Next, the $\mathrm{CNBr}$-activated
Sepharose 4B was mixed with the antibody solubilized in the same bicarbonate-buffered saline at a concentration of $1.0 \mathrm{mg} / \mathrm{ml}$. The ligand was then allowed to react with the activated gel for 3.5 $\mathrm{h}$ at room temperature. Subsequently, the reaction was stopped by placing the gel onto a sintered glass filter and washing with 15 column volumes of coupling buffer. The gel was then mixed with three column volumes of $0.2 \mathrm{M}$ ethanolamine for 2 $\mathrm{h}$ at room temperature. After stopping the reaction, the gel-ligand preparation was placed on a sintered glass filter and subjected to alternating washes (five times with ten column volumes of each) with bicarbonate-buffered saline, $\mathrm{pH} 8.2$, followed by $0.1 \mathrm{M}$ acetate buffer containing $0.5 \mathrm{M}$ $\mathrm{NaCl}, \mathrm{pH} 4.0$. It was then poured into a $1.5 \times 20$ cm Econo-column (Bio-Rad, Richmond, CA) with $0.05 \mathrm{M}$ phosphate buffer containing $0.15 \mathrm{M} \mathrm{NaCl}$, $\mathrm{pH} 7.2$, and $0.2 \%$ sodium azide.

(B) Schneider crosslinking technique (Schneider et al., 1982). Recombinant protein A-agarose (Repligen, Cambridge, MA), selected for its high IgG binding capacity, was poured with PBS into a $1.5 \times 20 \mathrm{~cm}$ Econo-column. Affinity purified antibody in $0.15 \mathrm{M} \mathrm{NaCl}$ was then passed over the gel. Unbound antibody was collected and reapplied to the column repeatedly until no further IgG would complex with the protein A matrix as indicated by UV absorbance at $280 \mathrm{~nm}$. Enough gel was used when pouring the column such that the IgG preparation saturated only $50 \%$ of the protein A binding sites. Bound antibody was next cross-linked to the protein A matrix by collecting the gel on a sintered glass filter and washing it with ten column volumes of $0.2 \mathrm{M}$ triethanolamine in $0.1 \mathrm{M}$ borate buffer, $\mathrm{pH}$ 8.2. The gel was then transferred from the sintered glass filter to a solution of $0.2 \mathrm{M}$ triethanolamine in $0.1 \mathrm{M}$ borate buffer containing $50 \mathrm{mM}$ dimethylpimelimidate prepared $1-3 \mathrm{~h}$ ahead of time. The $\mathrm{pH}$ of this crosslinking solution was readjusted to 8.2 with concentrated $\mathrm{NaOH}$. The gel crosslinking solution mixture was continuously agitated for $45 \mathrm{~min}$ at which time the reaction was stopped by first washing the gel on a sintered glass filter with 20 column volumes of $50 \mathrm{mM}$ ethanolamine, $\mathrm{pH} 8.2$, and subsequently reacting the gel with 20 column volumes of the same $50 \mathrm{mM}$ ethanolamine buffer for $5 \mathrm{~min}$. Finally, after terminating the crosslink- 
ing reaction, the gel-antibody complex was poured back into a $1.5 \times 20 \mathrm{~cm}$ Econo-column with PBS containing $0.02 \%$ sodium azide.

(C) Experimental modification of Schneider's technique: increased reaction time. The Schneider procedure described above was repeated except that the antibody-protein $\mathrm{A}$ complex was reacted with previously prepared $50 \mathrm{mM}$ of dimethylpimelimidate in $0.1 \mathrm{M}$ borate buffer containing $0.2 \mathrm{M}$ triethanolamine, $\mathrm{pH} 8.2$, for $2 \mathrm{~h}$ instead of the prescribed $45 \mathrm{~min}$.

(D) Experimental modification of Schneider's technique: increased crosslinker concentration. The Schneider procedure was used except that the antibody-protein A complex was reacted with 100 $\mathrm{mM}$ of dimethylpimelimidate in $0.1 \mathrm{M}$ borate buffer containing $0.2 \mathrm{M}$ triethanolamine, $\mathrm{pH} 8.2$, instead of the $50 \mathrm{mM}$ crosslinker concentration. The reaction was carried out for $45 \mathrm{~min}$.

(E) Experimental modification of Schneider's technique: repeated crosslinking reactions with freshly prepared crosslinker solution. The Schneider method was repeated except that the gel antibody complex was reacted twice with $50 \mathrm{mM}$ crosslinker with each reaction lasting for $45 \mathrm{~min}$. In addition, the triethanolamine borate buffer solution containing the $50 \mathrm{mM}$ dimethylpimelimidate was prepared immediately before mixing it with the gel antibody complex as opposed to making up the solution hours ahead of time.
Testing the capacity of the columns

Preparations containing known quantities of either human albumin or CTAP-III as determined by a UV method (Waddel, 1956) or by radial immunodiffusion (RID) (Castor and Cabral, 1988) were passed over each of the affinity columns in PBS. The column fractions containing the unbound material and the eluted antigen were then analyzed for purity using SDS-PAGE (Castor and Cabral, 1988) and for protein by the same UV and RID methods noted above.

\section{Results}

The characteristics of columns constructed by the Schneider and cyanogen bromide techniques are illustrated in Table I. The row headed 'Method symbol' denotes the procedure used to generate each column; the letters refer to the procedures described in the materials and methods section. The row headed 'Antigen' specifies the purified protein against which the antibodies employed in constructing the column were raised. The row headed 'Antigen binding capacity' defines the maximum amount of specific protein each $\mathrm{IgG}$ linked column is capable of binding when exposed to a preparation containing saturating amounts of antigen.

TABLE I

CHARACTERISTICS OF COLUMNS PREPARED WITH CNBr (A) AND PROTEIN A-AGAROSE (B) ${ }^{a}$

\begin{tabular}{|c|c|c|c|c|c|c|c|}
\hline & Method symbol: & A & $\mathrm{B}$ & B & A & $\mathrm{B}$ & B \\
\hline & Antigen: & Albumin & Albumin & Albumin & CTAP - III & CTAP-III & CTAP-III \\
\hline IgG applied & & $37.0 \mathrm{mg}$ & $5.6 \mathrm{mg}$ & $7.11 \mathrm{mg}$ & $88.7 \mathrm{mg}$ & $42.5 \mathrm{mg}$ & $41.0 \mathrm{mg}$ \\
\hline IgG X-linked & & $35.5 \mathrm{mg}$ & $2.61 \mathrm{mg}$ & $4.3 \mathrm{mg}$ & $76.1 \mathrm{mg}$ & - & - \\
\hline Coupling efficiency & & $96 \%$ & $41 \%$ & $61 \%$ & $86 \%$ & - & - \\
\hline \multicolumn{8}{|l|}{ Antigen binding } \\
\hline capacity (theory) & & $31.2 \mathrm{mg}$ & $2.30 \mathrm{mg}$ & $3.82 \mathrm{mg}$ & $9.44 \mathrm{mg}$ & - & - \\
\hline \multicolumn{8}{|l|}{ Antigen binding } \\
\hline capacity (actual) & & $1.6 \mathrm{mg}$ & $0.303 \mathrm{mg}$ & $0.40 \mathrm{mg}$ & $2.2 \mathrm{mg}$ & $0.329 \mathrm{mg}$ & $0.290 \mathrm{mg}$ \\
\hline \multicolumn{8}{|l|}{ Antigen binding } \\
\hline efficiency & & $5.13 \%$ & $13.2 \%$ & $10.5 \%$ & $23 \%$ & $6.2 \%^{\mathrm{b}}$ & $5.7 \%^{\mathrm{b}}$ \\
\hline
\end{tabular}

a $B$ represents method of Schneider et al. (1982).

b Reflects 'apparent antigen efficiency' and assumes $100 \%$ crosslinking of antibody to column; this is shown not to be true in Fig. 1. 


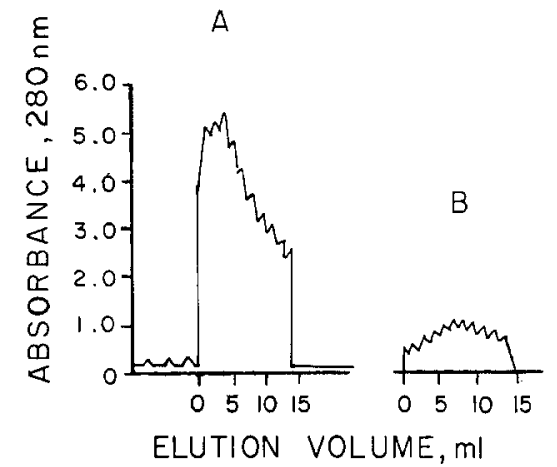

Fig. 1. $A$ illustrates the UV monitor trace during the initial elution ( $\mathrm{pH} 3.0$ ) of a column freshly prepared by the method of Schneider et al. (1982). The trace in $B$ reflects column performance where a similar amount of IgG was immobilized by method E. Protein lost by acid elution was shown to be $\operatorname{IgG}$ by immunodiffusion against IgG antisera; protein measurement showed the acid elution loss of IgG was reduced by more than $80 \%$ when immobilized by method $\mathrm{E}$.

Table I also shows the amount of immunoglobulin initially employed to generate each column, the amount of the original IgG permanently crosslinked to the column matrix, the theoretical binding capacity of the immobilized immunoglobulin, and the coupling efficiency. The theoretical binding capacity of a column is calculated as the number of moles of $\operatorname{IgG}$ (that which remained coupled to the column support), multiplied by 2 (assuming a divalent antibody), and then multiplied by the molecular weight of the antigen for which the antibody is specific. The efficiency of a particular column was defined as the column's actual binding capacity divided by its theoretical binding capacity multiplied by 100 . Finally, the coupling efficiency is defined as the amount of immunoglobulin permanently immobilized to the column matrix divided by the initial amount of antibody invested in constructing the column and converted into a percentage.

The data in Table I depict the shortcomings of columns constructed by both the Schneider and cyanogen bromide techniques. With one exception, the efficiencies of the columns do not exceed 15\%. The low efficiencies of columns constructed by the cyanogen bromide procedure occur despite coupling efficiencies of greater than $85 \%$.

Fig. $1 A$ shows a UV absorbance $(280 \mathrm{~nm})$ trace which illustrates the elution of antibody crosslinked to protein A by the Schneider technique on initial exposure to $0.1 \mathrm{M}$ glycine- $\mathrm{HCl}, \mathrm{pH} 3.0$. Similar traces were seen with modifications $\mathrm{C}$ and D. Fig. $1 B$ illustrates the reduced quantity of immunoglobulin separated from the gel matrix of a column constructed by procedure $\mathrm{E}$ upon first exposure to glycine- $\mathrm{HCl}, \mathrm{pH} 3.0$ solution.

Table II records the characteristics of columns constructed by modifications of the Schneider procedure. The row headings are identical to those found in Table I. The methods noted in Table II are those described in the materials and methods section. The data in this table suggest that modifications of crosslinker concentration and reaction time do not influence the stability of the couple between the IgG and the protein A. Columns constructed using these manipulations display efficiencies of less than $17 \%$. Matrices constructed

TABLE II

CHARACTERISTICS OF COLUMNS PREPARED WITH MODIFICATIONS OF THE DIMETHYLPIMELIMIDATE CROSSLINKING METHOD

\begin{tabular}{|c|c|c|c|c|c|c|c|}
\hline & Method symbol: & $\mathrm{C}$ & $\mathrm{D}$ & $\mathrm{E}$ & $\mathrm{E}$ & $\mathrm{E}$ & $\mathbf{E}$ \\
\hline & Antigen: & Albumin & Albumin & Albumin & CTAP-III & CTAP-III & CTAP-III \\
\hline$\overline{\text { IgG applied }}$ & & $5.6 \mathrm{mg}$ & $4.7 \mathrm{mg}$ & $3.76 \mathrm{mg}$ & $5.33 \mathrm{mg}$ & $37.5 \mathrm{mg}$ & $33.12 \mathrm{mg}$ \\
\hline IgG X-linked & & $31.8 \mathrm{mg}$ & $1.81 \mathrm{mg}$ & $3.04 \mathrm{mg}$ & $5.33 \mathrm{mg}$ & $36.5 \mathrm{mg}$ & $32.7 \mathrm{mg}$ \\
\hline Coupling efficiency & & $56.8 \%$ & $38.5 \%$ & $80.8 \%$ & $100 \%$ & $97.3 \%$ & $98.7 \%$ \\
\hline $\begin{array}{l}\text { Antigen binding } \\
\text { capacity (theory) }\end{array}$ & & $2.80 \mathrm{mg}$ & $1.59 \mathrm{mg}$ & $2.68 \mathrm{mg}$ & $0.660 \mathrm{mg}$ & $4.53 \mathrm{mg}$ & $4.05 \mathrm{mg}$ \\
\hline $\begin{array}{l}\text { Antigen binding } \\
\text { capacity (actual) }\end{array}$ & & $0.424 \mathrm{mg}$ & $0.267 \mathrm{mg}$ & $1.06 \mathrm{mg}$ & $0.690 \mathrm{mg}$ & $4.63 \mathrm{mg}$ & $3.77 \mathrm{mg}$ \\
\hline $\begin{array}{l}\text { Antigen binding } \\
\text { efficiency }\end{array}$ & & $15.1 \%$ & $16.8 \%$ & $39.6 \%$ & $104 \%$ & $102 \%$ & $93.1 \%$ \\
\hline
\end{tabular}


by repeating the crosslinking reaction, however, do exhibit substantial improvement. The coupling efficiencies for this latter group are greater than $80 \%$ and the column efficiencies are, with one exception, greater than $80 \%$.

\section{Discussion}

The rapid decrease in $\mathrm{pH}$ of the $50 \mathrm{mM}$ dimethylpimelimidate solution during the crosslinking procedure provided the motivation to modify the procedure in two ways. First, the number of coupling reactions used to generate each immunoaffinity column was increased, and secondly the crosslinker solution was prepared immediately prior to matrix construction. Gersten and Marchalonis (1978) reported that at a low $\mathrm{pH}$, the hydrolysis of the crosslinker is favored over the linking reaction. The change in $\mathrm{pH}$ after 45 min suggested that all the original dimethylpimelimidate was either involved in crosslinking or hydrolyzed so that increasing the coupling reaction time would not increase the coupling efficiency. This conclusion is supported by the failure of the increased reaction time procedure to improve the efficiency of columns generated by this technique. Repeatedly adding fresh dimethylpimelimidate solution to the IgG-protein A-agarose provided a means to enhance the linkage between the matrix and immunoglobulin.

The relatively low antigen binding capacities of antibody-coupled affinity columns generated by both the conventional cyanogen bromide crosslinking procedure and the novel method developed by Gersten and Marchalonis and modified by Schneider et al. are denoted in Table I. The cyanogen bromide technique, as indicated by the high crosslinking efficiencies of columns constructed by this method, allows for stable binding of antibody to the gel support. The poor antibody binding capacities of the cyanogen bromide generated matrices, despite the successful immobilization of nearly all the original antibody, suggests the antibody is linked randomly without protection of the variable antigen binding regions.

The reduced antigen binding efficiencies of columns constructed by Schneider's technique, also depicted in Table I, result primarily from insuffi- cient immobilization of the initial antibody to the protein A-agarose matrix and not from the random orientation of immunoglobulin coupled to the column support. The low crosslinking efficiencies (Table I) and the large antibody elution peak upon initial exposure of the gel matrix to $\mathrm{pH}$ 3.0 buffer (Fig. 1) substantiate the instability of the bridge between the $\operatorname{IgG}$ molecule and the column support. In addition, Table I indicates that antibodies, permanently immobilized by the Schneider technique, bind $20 \%$ or less of their theoretical capacity of specific protein. This may indicate either that the immunoglobulins immobilized on protein $A$ at their $F c$ region are not optimally arranged to bind antigen or that the dimethylpimelimidate crosslinker in some way interferes with the variable regions of the IgG molecule. Schneider presented data that contradicted these two possible sources of protein binding site interference; it suggested that, if the immobilized IgG could be more tightly secured to the protein A-agarose, immunoaffinity columns with antigen capacities approaching theory could be generated. Their conclusion provided the impetus to modify several steps of Schneider's procedure with the goal of increasing the antibody-matrix stability under acidic elution conditions.

As Table II exhibits, two modifications tested (the increased reaction time treatment and the increased crosslinker concentration treatment) did not enhance the stability of the antibody-protein A complex under low $\mathrm{pH}$ conditions relative to columns generated by the unmodified Schneider procedure. However, performing consecutive 50 $\mathrm{mM}$ dimethylpimelimidate incubations did significantly increase the strength of the couple under acidic conditions. Crosslinking efficiencies of greater than $80 \%$ (Table II), and a small elution peak upon first exposure of the gel to an acidic buffer (Fig. 1), provide evidence for this improved linkage.

The high antigen binding efficiencies for the anti-CTAP-III coupled columns produced by the repeated crosslinking technique (Table II) indicate, as concluded by Schneider, that the antibody is stationed on the gel matrix in an orientation that allows maximal antigen binding and that the dimethylpimelimidate crosslinker does not interfere with the variable regions of the IgG molecule. 
This data, however, is inconsistent with the behavior of columns constructed by the unmodified Schneider method in our laboratory. The discrepancy most likely arises from a failure to account for all the immunoglobulin separated from the agarose support during the several washes called for in the Schneider procedure. Not accounting for these losses would result in an overestimation of the amount of crosslinked IgG and thus an overestimation of the theoretical binding capacity of the column which would ultimately lead to calculations of poor antigen binding efficiencies.

In summary, modifying Schneider's procedure by repeating the crosslinking reaction with freshly prepared $50 \mathrm{mM}$ dimethylpimelimidate solution has allowed the generation of immunoaffinity matrices which isolate multimilligram amounts of pure antigen with a single column pass. This capability has made the study of otherwise difficult to purify polypeptide growth factors much more feasible. This technique, by securely fastening the IgG to the Protein A-agarose, prevents the wastage of antibodies which are difficult to produce and equally difficult to purify.

\section{Acknowledgements}

We are indebted to Virginia Castor for preparation of the figure, and to Mary Helen Gilbert for typing the manuscript.

\section{References}

Axen, R., Porath, J. and Ernback, S. (1967) Chemical coupling of peptides and proteins to polysaccharides by means of cyanogen halides. Nature 214, 1302.

Castor, C.W. and Cabral, A.R. (1988) Connective tissue activating peptides. In: G. Sabato (Ed.), Methods in Enzymology. Academic Press, Orlando, FL.

Castor, C.W., Miller, J.W. and Walz, D.A. (1983) Structural and biological characteristics of connective tissue activating peptide (CTAP-III), a major human platelet-derived growth factor. Proc. Natl. Acad. Sci. U.S.A. 80, 765 ,

Castor, C.W., Walz, D.A., Ragsdale, C.G., Hossler, P.A., Smith, E.M., Bignall, M.C., Aaron, B.P. and Mountjoy, K. (1989) Connective tissue activation. XXXIII: Biologically active cleavage products of CTAP-III from human platelets. Biochem. Biophys. Res. Commun. 163, 1071.

Gersten, D.M. and Marchalonis, J.J. (1978) A rapid method for the solid phase derivatization of IgG antibodies for immune-affinity chromatography. J. Immunol. Methods 24, 303.

Schneider, C., Newman, R.A., Sutherland, D.R., Asser, U. and Greaves, M.F. (1982) A one-step purification of membrane proteins using a high efficiency immunomatrix. J. Biol. Chem, 257, 10766.

Waddel, W.J. and Hill, C. (1956) A simple ultraviolet spectrophotometric method for the determination of protein. J. Lab. Clin. Med. 48, 211. 